\title{
GEOPOLÍTICA E MEIOS DE COMUNICAÇÃO: A INFLUÊNCIA DOS ESTER EÓTIPOS DIFUNDIDOS PELA MÍDIA SOBRE A CIVILIZAÇÃO MUÇULMANA NO PROCESSO DE ENSINO -APRENDIZAGEM EM GEOGRAFIA NO ENSINO BÁSICO
}

\author{
Francisco Fernandes Ladeira (UFSJ)
}

Vicente de Paula Leão

(UFSJ)

\section{RESUMO}

$\mathrm{O}$ atentado de 11 de setembro gerou, entre outras consequências, uma intensa e poderosa campanha midiática global contra a civilização muçulmana. Não obstante, os estereótipos negativos sobre o islã e seus seguidores encontraram um campo fértil para a sua propagação nos noticiários da imprensa brasileira. Desse modo, a partir do pressuposto de que a mídia tem desempenhado o papel de influente ator no atual contexto das relações internacionais, o presente trabalho aborda a influência dos principais veículos de comunicação no processo de ensino-aprendizagem em Geografia no Ensino Básico. Primeiramente, apresentamos os mecanismos persuasivos utilizados pelos meios de comunicação de massa para, posteriormente, analisarmos como o professor de Geografia trabalha com o material midiático em sala de aula. Neste estudo constatou-se que, apesar de não possuir o mesmo poder de convencimento registrado em outras épocas, o discurso midiático, no tocante às questões geopolíticas, ainda é o principal fator que condiciona tanto a formação de opinião do professor quanto à construção do conhecimento por parte dos alunos. Ademais, grande parte dos docentes ainda concebe o material midiático apenas como mais um recurso didático e não como objeto de estudo a ser sistematizado em sala de aula.

Palavras-chave: mídia, geografia, muçulmanos, professor, ensino-aprendizagem.

\section{INTRODUÇÃO}

Ao longo da história, as grandes potências mundiais geralmente recorreram à prática de forjar a existência de determinados inimigos externos como maneira de legitimar suas políticas expansionistas.

Desde os povos bárbaros, durante a Idade Antiga; passando pelos "selvagens" na época dos grandes impérios coloniais e chegando aos muçulmanos dos dias hodiernos, a presença supostamente ameaçadora e incômoda do "outro" é incessantemente utilizada como pretexto para escamotear as mais diversas formas de dominação.

Após as duas grandes guerras mundiais, o centro hegemônico global descolou-se da Europa Ocidental para os Estados Unidos da América.

Durante as primeiras décadas de domínio estadunidense, o principal inimigo externo de Washington foi o comunismo, representado pela União Soviética.

Desse modo, toda uma gama de propaganda ideológica foi utilizada para amedrontar a população sobre o "perigo vermelho".

No início dos anos 1990, o colapso da União Soviética, o suposto triunfo do 


\section{SEMINÁRIO DE PESQUISA EM CIÊNCIAS HUMANAS - SEPECH \\ Humanidades, Estado e desafios didático-científicos \\ Londrina, 27 a 29 de julho de 2016}

capitalismo e da democracia burguesa frente à alternativa socialista e a ilusão do "Fim da História" fizeram com que muitos analistas acreditassem que os Estados Unidos não necessitariam mais de um bode expiatório para justificar suas ações imperialistas.

Entretanto, após os atentados ao World Trade Center (WTC) e ao Pentágono, atribuídos à rede $\mathrm{Al}$ Qaeda, liderada pelo saudita Osama Bin Laden, em 11 de setembro de 2001, surge um novo inimigo externo dos Estados Unidos (e consequentemente da civilização ocidental): o "terrorista islâmico".

A partir de então teve início uma intensa campanha midiática com o objetivo de demonizar o mundo muçulmano. Imagens dos aviões se chocando com as torres gêmeas do WTC e de muçulmanos supostamente celebrando esses ataques foram exaustivamente repetidas em todo o planeta.

Não obstante a propaganda ideológica contra a civilização muçulmana promovida pelas mídias estadunidense e europeia, a grande mídia brasileira, subserviente aos interesses das grandes potências mundiais, também aderiu ao discurso tendencioso produzido por Washington e aliados.

Tatiana Alvim (2003) afirma que a cobertura sobre o 11 de setembro apresentou uma espécie de "efeito cascata", em que a imprensa estadunidense divulgava os seus relatos dos fatos, a mídia brasileira reproduzia o discurso padronizado de Washington e os jornais regionais (até então alheios a assuntos externos) resumiam as matérias dos grandes veículos da imprensa nacional, fechando o ciclo.

As causas do atentado não foram reveladas ou então tidas como inexistentes e as mesmas expressões (ou similares) adotadas na mídia dos Estados Unidos foram replicadas como verdades unânimes pelos principais jornais e redes de televisão brasileiras.

Nesse sentido, o presente trabalho busca compreender a influência dos estereótipos difundidos pela mídia sobre o mundo muçulmano no processo de ensinoaprendizagem em Geografia no ensino básico.

\section{A IMPORTÂNCIA DA MÍDIA PARA A ORDEM GEOPOLÍTICA CONTEMPORÂNEA}

A expressão "ordem geopolítica" é utilizada para representar os jogos de poder e equilíbrio de forças que caracterizam as relações internacionais em um determinado contexto histórico.

Já a "Geopolítica", enquanto campo do conhecimento, se refere às análises das relações internacionais, distribuição espacial do poder, emergência de atores nãoestatais no cenário global e relações entre Estado-Nacional e território.

Após a Segunda Guerra Mundial, o relativo enfraquecimento do setor público em detrimento do avanço de forças privadas e as inovações tecnológicos, notadamente nos setores de comunicação e transporte, fizeram com que atores como a mídia, o capital desterritorializado, os organismos supranacionais, os blocos regionais, as organizações não-governamentais (ONGs) e as corporações transnacionais passassem a dividir espaço com os tradicionais Estados- Nacionais no cenário geopolítico global.

As novas hipóteses geopolíticas partem do pressuposto de que questões econômicas, sociais, culturais, e simbólicas são tão importantes quanto o poderio militar como instrumentos de análise para compreender o equilíbrio de forças e a busca por hegemonia em âmbito global. 


\title{
XI SEMINÁRIO DE PESQUISA EM CIÊNCIAS HUMANAS - SEPECH \\ Humanidades, Estado e desafios didático-científicos \\ Londrina, 27 a 29 de julho de 2016
}

No livro Discursos Geopolíticos da Mídia - Jornalismo e Imaginário Internacional na América Latina, Margarethe Steinberger (2005) apresenta a tese de que nova ordem geopolítica internacional é uma ordem internacional midiática.

Segundo a autora, as diferentes formas de imperialismo cultural (que não implicam necessariamente em domínio territorial físico e direto) e de soft power (capacidade de conseguir resultados por meio da atração em vez da coerção) indicam que o sistema de referência em ascensão é o sistema "pós-moderno midiático", em que a indústria cultural e os meios de comunicação de massa detêm o poder de configurar mentalidades a médio/longo prazo e, portanto, amalgamar o apoio social necessário à consolidação de qualquer liderança global.

A mídia possui o poder de definir, segundo seus interesses, o que deve ou não ser do conhecimento do grande público, de divulgar em escala planetária os principais acontecimentos mundiais, sob sua ótica. Assim, a informação que recebemos passa por um processo de edição no qual predominam a fragmentação da notícia e a visão ideológica viés - daqueles que controlam o poder de informar (LEÃO; CARVALHO LEÃO, 2008, p. 17).

$\mathrm{Na}$ atual configuração das relações internacionais a mídia também tem assumido o papel de uma "esfera pública internacional sem fronteiras". Ou seja, é uma instância de mediação em que os diferentes atores geopolíticos (hegemônicos e contrahegemônicos) apresentam seus argumentos para convencer o público à aderir a uma determinada agenda política ou corrente ideológica.

De acordo com a teoria construtivista, os grandes veículos de comunicação são atores extremamente relevantes na configuração das relações internacionais, pois "na sociedade da informação, a política internacional não é somente feita por meio da mídia, mas também percebida através dela" (CAMARGO, 2012, p. 136).

\begin{abstract}
A teoria construtivista permite entender o papel da mídia nas Relações Internacionais e, especificamente, por meio das reflexões dos modernistas-linguistas é possível compreender como linguagem e discurso constituem a realidade internacional. [...] Partindo de uma tradição interpretativa, concentra seu esforços na compreensão dos significados e nas construções das práticas sociais e culturais. Em outras palavras, defende que a realidade é socialmente construída. (IDEM, p. 37).
\end{abstract}

Consequentemente, a mídia tem sido um importante mecanismo para fomentar ou legitimar uma determinada agenda geopolítica.

Na obra Manufacturing Consent, Noam Chomsky e Edward Herman (1994) destacam que a atuação dos meios de comunicação de massa pode ser entendida a partir de um modelo retirado da propaganda, isto é, as atividades desenvolvidas pela mídia em geral estão a serviço da mobilização de apoio a interesses especiais que dominam o Estado e a atividade privada, construindo "fatos" e "verdades".

Sendo assim, podemos compreender as atuais questões geopolíticas a partir do tripé governo/academia/mídia, em que os principais líderes globais lançam determinadas agendas ("guerra ao terror"), alguns pensadores as corroboram 


\section{SEMINÁRIO DE PESQUISA EM CIÊNCIAS HUMANAS - SEPECH \\ Humanidades, Estado e desafios didático-científicos \\ Londrina, 27 a 29 de julho de 2016}

intelectualmente ("choque de civilizações") $)^{1}$ e a mídia tem por função legitimar e tornar compreensível os discursos políticos e acadêmicos frente à população ("consenso fabricado").

Segundo a teoria conhecida por CNN Effect, a mídia não possui apenas um papel secundário de difundir uma determinada agenda política, mas influencia diretamente a atuação governamental, chegando a interferir em algumas tomadas de decisão, sobretudo em assuntos relacionados às intervenções militares. Indubitavelmente, um acontecimento que não esteja "documentado" na mídia não "existe" sob o ponto de vista geopolítico.

Seguindo essa linha de raciocínio, Eytan Gilboa (2002) cunhou o termo "diplomacia midiática" para corroborar seu argumento de que a diplomacia tradicional, com negociações fechadas feitas entre diplomatas e governo, desconhecidas do grande público, foi substituída por uma nova maneira de diplomacia - a "diplomacia na era da mídia”, propiciada pela revolução da informação ocorrida durante o século XX.

Gilboa entende que a mídia não é somente como um mero instrumento ao qual um determinado Estado recorre para alcançar seus interesses, mas é um ator extremamente relevante nas Relações Internacionais, pois na "Era da Informação", os meios de comunicação e os jornalistas representam uma espécie de "quarto poder" que atua ativamente como intermediário para a construção de relações de comunicação e confiabilidade entre Estados e atores não-estatais, nas negociações de conflitos e também procurando mobilizar o apoio público para acordos internacionais.

Media diplomacy is pursued through various routine and special media activities including press conferences, interviews and leaks, as well as visits of heads of state and mediators to rival countries and spectacular media events organized to usher in new policy eras. [...] Prominent journalists have even occasionally assumed the role of diplomats, both in crises and peacemaking situations. These uses of the media have had significant impact on the conduct and coverage of diplomacy. (GILBOA, 2007, pp. 10,23).

Apesar de ainda não haver uma teoria que consiga abranger e explicar satisfatoriamente as complexas interações entre mídia e geopolítica, é consenso entre analistas de que a hegemonia no âmbito das atuais relações internacionais depende cada vez mais do desenvolvimento tecnológico na área informacional.

\footnotetext{
${ }^{1}$ Choque de civilizações é uma hipótese proposta pelo cientista político Samuel Huntington (1997). Segundo essa proposição, no cenário geopolítico pós-Guerra Fria, as fontes de conflitos não seriam mais razões ideológicas ou econômicas, mas questões de ordem cultural, sobretudo as rivalidades entre civilizações. O grande equívoco de se adotar o "choque de civilizações" como paradigma para se entender os principais focos de tensão do atual contexto geopolítico é não levar em consideração as motivações econômicas que condicionaram as intervenções das potências ocidentais em países como Afeganistão, Iraque, Líbia e Síria. Interpretar tais conflitos como meros antagonismos intercivilizacionais, ou somente levando em consideração as diferenças entre as religiões cristã e muçulmana, é simplificar demasiadamente uma realidade que é inerentemente complexa.
} 


\section{SEMINÁRIO DE PESQUISA EM CIÊNCIAS HUMANAS - SEPECH \\ Humanidades, Estado e desafios didático-científicos \\ Londrina, 27 a 29 de julho de 2016}

Em outros termos, o processo de dominação de uma nação sobre outras não se restringe apenas ao espectro militar, também está relacionado ao campo discursivo.

Além de um poderoso exército, uma grande potência contemporânea também deve utilizar um eficiente aparato midiático, capaz de difundir determinadas ideias em escala planetária.

\section{CIVILIZAÇÃO MUÇULMANA NA MÍDIA BRASILEIRA}

Apesar de seu considerável poder de persuasão, nos últimos anos a grande imprensa brasileira tem perdido paulatinamente o monopólio de tentar moldar a opinião pública nacional.

O advento das redes sociais e a chamada "mídia independente" têm proporcionado visões alternativas de determinados acontecimentos, exemplos que vêm assim contribuindo como contrapontos ao status quo.

Entretanto, no tocante às questões internacionais, em que o ponto de vista alternativo ao pensamento hegemônico é menos eficaz e abrangente, a grande imprensa (principalmente a maior emissora de TV do país) ainda é a principal referência para boa parte da população.

Nesse contexto, a ideologia imperialista da mídia estadunidense, fielmente difundida pelos seus congêneres brasileiros, é praticamente a única fonte de informações que chega à esmagadora maioria da audiência.

Para facilitar a compreensão do público (em geral não familiarizado com as temáticas geopolíticas) e tornar inteligível a complexa configuração das relações internacionais, a mídia fornece "atalhos cognitivos", a partir de estereótipos, maniqueísmos e personificações.

Desse modo, estereótipos como o "muçulmano terrorista e fanático religioso", o "ditador cubano" e o "caudilho sul-americano", exaustivamente repetidos como mantras pelos meios de comunicação, podem ser aceitos sem maiores questionamentos.

A cobertura realizada pelo Jornal Nacional sobre o atentado de 11 de setembro foi marcada pela intensa exploração de aspectos subjetivos da personalidade humana.

Com expressões mais sérias do que o habitual, os âncoras Willian Bonner e Fátima Bernardes recorreram a frases de efeito como "uma terça-feira que vai marcar a história da humanidade", "o maior atentado terrorista de todos os tempos", "bolsas de valores e moedas nacionais são abaladas pelos atentados", "a maior potência do planeta é alvejada pelo terror", "o planeta em alerta geral" e "nunca na história tantos aviões foram sequestrados ao mesmo tempo"2.

Enquanto a população estadunidense foi caracterizada como exemplo de solidariedade e superação diante das adversidades, muçulmanos foram retratados como extremistas que celebravam o "banho de sangue" promovido pela Al Qaeda. Willian Bonner chegou a apontar que "nos territórios ocupados por Israel palestinos comemoravam a maior ofensiva terrorista de todos os tempos". Por sua vez, o repórter Ernesto Paglia acrescentou:

\footnotetext{
${ }^{2}$ Giani David-Silva (2008) assevera que os diferentes níveis de tensão presentes na narrativa do Jornal Nacional fazem parte de um eficaz conjunto de estratégicas que visam assegurar a audiência do programa.
} 


\section{SEMINÁRIO DE PESQUISA EM CIÊNCIAS HUMANAS - SEPECH \\ Humanidades, Estado e desafios didático-científicos \\ Londrina, 27 a 29 de julho de 2016}

Terror na América, festa no Oriente Médio. Nas ruas dos territórios palestinos ocupados por Israel, os americanos são vistos como amigos do inimigo israelenses. Portanto, inimigos que merecem o pior. Há muita gente disposta a festejar a desgraça alheia diante das câmeras internacionais ${ }^{3}$.

De maneira geral, o telejornal limitou-se a exibir incessantemente imagens dos aviões se chocando com as torres gêmeas do World Trade Center e de pessoas se jogando desesperadamente de ambos os edifícios em vez de contextualizar e analisar criticamente o quadro geopolítico que condicionou as ações da rede Al Qaeda contra os Estados Unidos, causando a falaciosa impressão de que o atentado de 11 de setembro não teve causas, mas somente consequências.

Sendo assim, grande parcela dos telespectadores pode equivocadamente inferir que os ataques promovidos por grupos como a $\mathrm{Al}$ Qaeda são comprovações de que a religião islâmica prega abertamente a intolerância e a violência ou, como sugeriu Thomas Friedman (2007) podem ter sido motivados simplesmente pela inveja que os muçulmanos sentem em relação aos êxitos do Ocidente, principalmente dos Estados Unidos.

Ingrid Gomes (2012) constatou em sua tese de doutorado que os editoriais internacionais dos jornais $O$ Estado de $S$. Paulo e Folha de $S$. Paulo nos quinze dias posteriores ao atentado de 11 de setembro foram marcados pelo uso de generalizações, simplificações, ausência de contextualização histórica e associações da civilização muçulmana à cultura inferior e arcaica.

Em uma pesquisa sobre análise de discurso, Manhães (2012) concluiu que a cobertura do jornal $O$ Globo sobre o 11 de setembro apresentou características típicas de narrativas épicas, sendo que o presidente dos Estados Unidos, George W. Bush, foi alçado ao status de herói e, em contrapartida, os terroristas islâmicos assumiram os papéis de vilões. Segundo o autor, as matérias do periódico carioca basearam-se na dicotomia entre civilização (Ocidente) e barbárie (Mundo Muçulmano), reduzindo o atentado à natureza truculenta do ato, sem levar em consideração a maneira autoritária com que os Estados Unidos conduzem sua política externa em relação aos países periféricos.

No artigo A Ocidentalização da Informação, Queiroz (2005) aborda o tratamento que a revista Veja confere ao mundo islâmico, bem como os desdobramentos da relação entre a civilização ocidental e mulçumana. De acordo com a autora, a publicação utiliza sistematicamente termos pejorativos para se referir aos povos do Oriente Médio e não se lança ao trabalho de distinguir com clareza um muçulmano civil

\footnotetext{
${ }^{3}$ As imagens de crianças e mulheres palestinas "comemorando" os acontecimentos em Nova York e Washington foram produzidas pela CNN e exibidas em todo o planeta. Contudo "poucos dias após o atentado começou a circular informações indicando que as imagens da CNN em que se via o suposto festejo de palestinos, eram manipuladas. Neste sentido, havia duas versões. A primeira afirmava que as imagens eram legítimas, ou seja, as crianças palestinas e as mulheres de fato festejavam, não o atentado porém, mas a invasão ao Kuwait de 1991, por parte do Iraque. A segunda destas versões dizia que as mulheres e crianças foram pagas para que festejassem. [...] Após o desmentido oficial da CNN as imagens não voltaram a ser transmitidas e lançou-se um véu de silêncio sobre o assunto" (ALVIM, 2003, p. 3).
} 


\section{SEMINÁRIO DE PESQUISA EM CIÊNCIAS HUMANAS - SEPECH \\ Humanidades, Estado e desafios didático-científicos \\ Londrina, 27 a 29 de julho de 2016}

de um terrorista, considerando assim que todo islamita é um terrorista potencial.

De maneira geral, as expressões utilizadas nas páginas da revista Veja para se referir aos muçulmanos são: "barbudos", "fanáticos islâmicos ensandecidos", "sociedades dos turbantes", "fascismo islâmico", "universo de turbantes" e "loucos de Alá".

Segundo a lógica jornalística de grande parcela da mídia brasileira, os ataques de grupos islâmicos contra os Estados Unidos, independentemente de serem reações radicais a constante presença estadunidense no Oriente Médio, são causados por bárbaros e atrasados muçulmanos que não aceitam os modernos valores ocidentais.

Frente a esse quadro, não basta que um cidadão se mantenha apenas informado, é preciso saber ler a mídia, desvendar seus possíveis mecanismos manipuladores e entender os jogos de interesse que estão por trás do seu discurso. Compreender o conteúdo do noticiário internacional como resultado de um complexo processo de construção social e cultural dos fenômenos geopolíticos.

O sujeito que possui o mínimo conhecimento sobre o maquinário midiático, seleção de pautas (agenda-setting) e o contexto de construção da notícia (newsmaking) dificilmente será um alvo vulnerável para o pensamento dominante, pois "conhecer os códigos lingüísticos utilizados pelo emissor amplia as possibilidades de leitura do codificador" (LEÃO; CARVALHO LEÃO, 2008, p. 98).

\section{MÍDIA E ENSINO DE GEOGRAFIA}

Diante da complexidade do atual cenário das relações internacionais, das divergências entre as diferentes correntes de interpretação geopolítica e do alinhamento ideológico da mídia brasileira às grandes potências mundiais, o professor de Geografia tem o grande desafio pedagógico de apresentar o conteúdo didático em uma linguagem adequada à compreensão de seus alunos, porém sem recorrer às mesmas simplificações e maniqueísmos utilizados pelos meios de comunicação.

Boa parte da programação midiática aborda (de maneira superficial) questões relacionadas à Geografia Escolar como globalização, conflitos geopolíticos, aquecimento global, problemas urbanos, fontes de energia, crescimento demográfico e desenvolvimento sustentável, entre outros temas.

De acordo com Leão (2003), o professor pode transformar qualquer texto midiático em material útil para o ensino de Geografia, desde que o ponto de partida para a sua reflexão seja o conhecimento geográfico.

Todavia, as instituições escolares devem estar preparadas para incorporar a linguagem dos grandes meios de comunicação, servindo-se dela sem ser por ela dominada (LEÃO; CARVALHO LEÃO, 2008).

Para tanto, torna-se necessário conhecer essa linguagem para que professores e alunos sejam interlocutores ativos e não receptores passivos do discurso midiático.

Nesse sentido, "a Geografia, enquanto disciplina escolar congrega vastas possibilidades de utilização do material produzido pela mídia" (IDEM, p. 42), pois os noticiários utilizam várias categorias de análise inerentes à ciência geográfica como espaço, território, lugar, não-lugar, territorialidade e escalas. 


\section{SEMINÁRIO DE PESQUISA EM CIÊNCIAS HUMANAS - SEPECH \\ Humanidades, Estado e desafios didático-científicos \\ Londrina, 27 a 29 de julho de 2016}

Questões complexas do xadrez geopolítico global, que estão entre as causas dos focos de tensão entre civilização muçulmana e civilização ocidental, como a constante presença de tropas das grandes potências mundiais em nações do Oriente Médio, a aliança entre Estados Unidos e Arábia Saudita - país onde está a cidade de Meca, local sagrado para a religião islâmica - e o apoio incondicional de Washington a Israel em suas disputas por territórios com o povo palestino podem ser compreendidas a partir de conceitos pilares da ciência geográfica.

Por meio da observação do cotidiano em sala de aula foi possível avaliar melhor quais os riscos e as diferentes possibilidades de utilização do material midiático no ensino de Geografia na escola básica.

Nossa estratégica metodológica foi constituída por três etapas. Em um primeiro momento, perguntamos a um grupo de alunos quais ideias lhes vinham à mente ao entrarem em contato com imagens que remetem à civilização muçulmana. Posteriormente, invertemos o processo, e solicitamos a outro grupo de estudantes que relatassem suas imagens acústicas sobre palavras que os meios de comunicação de massa geralmente utilizam em noticiários internacionais.

$\mathrm{Na}$ segunda etapa, observamos os valores e conceitos presentes nos discursos dos professores sobre a civilização muçulmana.

$\mathrm{Na}$ terceira etapa, comparamos as diferentes concepções de professores e alunos com os conteúdos dos noticiários sobre o mundo muçulmano.

Boa parte professores ainda tem os grandes veículos de comunicação como principais referências para as suas aulas sobre geopolítica.

Mesmo os educadores que possuem discursos relativamente alheios a ideologia midiática ainda apresentam dificuldades didáticas como relacionar questões geopolíticas com o conhecimento geográfico, contextualizar histórica e espacialmente os conflitos entre Ocidente e civilização islâmica, imposição do ponto de vista docente aos alunos ou trabalhar com o material midiático apenas como mais um recurso didático e não como objeto de estudo a ser sistematizado.

Desse modo, ao não sistematizar conceitos-chave do léxico geopolítico em sala de aula ou ocultar os jogos de poder e interesses ideológicos que estão por trás da utilização de determinadas palavras, o professor contribui para que seus alunos reverberem simplificações, preconceitos e maniqueísmos presentes nos discursos midiáticos e no senso comum.

Para a maioria dos estudantes que participaram desde trabalho, as imagens acústicas correspondentes à palavras como "terrorismo" e "fanatismo" remetem a homens com turbantes, ataques a grandes cidades do mundo ocidental ou jovens barbados empunhando armas.

Por outro lado, após análise de diversas matrizes curriculares, constatamos que as relações entre mídia e processo educacional ainda são pouco abordadas nos cursos de licenciatura em geral, fator que dificulta a formação de profissionais que estejam preparados para trabalhar com o material midiático em sala de aula.

\section{CONSIDERAÇÕES FINAIS}

Entende-se que cabe ao educador promover a ressignificação do discurso midiático em sala de aula e orientar seus alunos no gerenciamento das informações que 


\section{SEMINÁRIO DE PESQUISA EM CIÊNCIAS HUMANAS - SEPECH \\ Humanidades, Estado e desafios didático-científicos \\ Londrina, 27 a 29 de julho de 2016}

estão disponíveis nos principais veículos de comunicação.

Em outros termos, fazer com que as instituições escolares sejam instâncias privilegiadas para a formação de cidadãos críticos em relação à mídia.

Surge assim um dos grandes desafios para os professores neste início de século 21: contribuir para que, no tocante aos estudos geopolíticos, o senso de julgamento de seus alunos não fique refém de um enquadramento midiático que busca explicações simplórias para os mais complexos temas da atualidade.

Assim, a problematização dialógica é um caminho para que uma formação adequada dos alunos seja colocada em prática, permitindo que estes sejam capazes de ir além daquilo que é veiculado na mídia.

Somente o pensamento crítico é capaz de capacitar os alunos para superação das simplificações e respostas prontas presentes no discurso midiático.

É fundamental que o aluno construa sua opinião a partir do conjunto de informações e ressignificações que the são disponibilizados. Cabe ao professor incentivá-lo a expressar suas opiniões e se posicionar diante dos fatos.

Toda crítica se fundamenta na autocrítica, desta forma, rever conceitos e concepções ideológicas constituem um dos caminhos para o desenvolvimento da capacidade de questionar, desconstruir e reconstruir a informação e, assim, produzir o conhecimento.

Um educador que manipula o conhecimento a favor de sua ideologia é intelectualmente tão pernicioso quanto um discurso midiático que distorce os fatos.

\section{REFERÊNCIAS}

ALVIM, Tatiana Gabriel. O uso da propaganda na guerra psicológica embutida nos meios de comunicação e seu estudo focado nas diretrizes do 11 de setembro. Barbacena: [s.n.], 2003. 39 p. Trabalho de Conclusão de Curso (Graduação em Publicidade e Propaganda)-Faculdade Regional de Ciências Exatas e Sociais - FACEC. Universidade Presidente Antônio Carlos - UNIPAC, Barbacena, 2003.

CAMARGO, Julia Faria. Mídia e Relações Internacionais: lições da Invasão do Iraque em 2003. 1. ed. (ano 2009) 2a reimpr. Curitiba: Juruá, 2012.

CHOMSKY, Noam; HERMAN, Edward. Manufacturing Consent. NY: Vintage Books, 1994.

DAVID-SILVA, Giani. Análise Semiolinguística da identidade midiático-discursiva de telejornais brasileiros e franceses. Glauks (UFV), v. 8, p. 10-19, 2008.

FRIEDMAN, Thomas L. $O$ mundo é plano: uma breve história do Século XXI. Tradução de Cristiana Serra, Sergio Duarte e Bruno Casotti. Rio de Janeiro: Objetiva, 2007.

GOMES, Ingrid. Olhares sobre o outro: Estudo das representações do Islã nos jornais Estado de S. Paulo e Folha de S. Paulo. Tese (Doutorado em Comunicação Social). Faculdade de Comunicação/UNESP, São Bernardo do Campo, 2012.

GILBOA, Eytan. Diplomacy in the media age: Three models of uses effects. Diplomacy 


\section{SEMINÁRIO DE PESQUISA EM CIÊNCIAS HUMANAS - SEPECH \\ Humanidades, Estado e desafios didático-científicos \\ Londrina, 27 a 29 de julho de 2016}

\& Statecraft, v. 12, n. 2, 2001, p. 1-28. Disponível em: $<$ http://dx.doi.org/10.1080/09592290108406201>. Acesso em: 12 abr. 2016.

HUNTINGTON, Samuel P. O choque de civilizações: e a recomposição da ordem mundial. Rio de Janeiro: Objetiva, 1997.

QUEIROZ, Ana Virginia Borges. A Ocidentalização Da Informação. Anais do XXVIII Congresso Brasileiro de Ciências da Comunicação - INTERCOM. Rio de Janeiro: UERG, 2005.

LEÃO, Vicente de Paula; CARVALHO LEÃO, Inêz Aparecida de. Ensino de Geografia e Mídia: linguagens e práticas pedagógicas. Belo Horizonte: Argumentum. 2008.

LEÃO, Vicente de Paula. O uso da mídia no ensino da geografia na educação básica. Dissertação (Mestrado em Geografia) - Universidade Federal de Minas Gerais - UFMG, Belo Horizonte, 2003.

MANHÃES. Eduardo. O dia da infâmia. In: PORTO, Sérgio Dayrell (org). A incompreensão das diferenças: 11 de setembro em Nova York. Brasília: IESB, 2002.

STEINBERGER, Margareth Born. Discursos geopolíticos da midia - jornalismo e imaginário internacional na América Latina. São Paulo: FAPESP, EDUC, CORTEZ, 2005. 